\title{
Moment redistribution in continuous steel-fibre-reinforced concrete slabs
}

Akshay Venkateshwaran $B E, P h D$

Department of Civil and Environmental Engineering,

National University of Singapore, Singapore

(Orcid:0000-0001-8171-0132)
Kiang Hwee Tan BEng, MEng, Dr Eng, PE

Department of Civil and Environmental Engineering, National University of

Singapore, Singapore (corresponding author: tankh@nus.edu.sg)

(Orcid:0000-0001-9013-0316)

The phenomenon of moment redistribution in steel-fibre-reinforced concrete (SFRC) members has not been adequately studied. In this study, the phenomenon was investigated by conducting point-load tests on seven two-span, one-way continuous slabs without traditional reinforcement. Significant redistribution of moments from the elastic values was observed at the critical mid-span and interior support sections. An analytical approach to predict the moment-curvature response of SFRC is presented, with which the predicted variation of moments with increasing load compared to the observed trends with reasonable accuracy. Also, the analytical approach predicts the load-carrying capacity of the slabs within $8 \%$ of the average observed values, with a standard deviation of $8 \%$. In addition, the load-deflection curves of the slabs were well predicted. The results are beneficial for the analysis and design of a SFRC slabs-on-pile system by considering moment redistribution due to slab continuity.

\section{Notation}

C area of compressive stress block

$D_{\mathrm{f}} \quad$ diameter of steel fibres $(\mathrm{mm})$

$E_{\mathrm{i}} \quad$ slope of descending portion of compressive stress-strain relation $(\mathrm{MPa})$

$E_{\mathrm{SFRC}} \quad$ modulus of elasticity of steel-fibre-reinforced concrete (SFRC) (MPa)

$f_{\mathrm{c}}^{\prime} \quad$ cylinder compressive strength of concrete (MPa)

$f_{\mathrm{ct}} \quad$ tensile strength of SFRC (MPa)

$f_{\mathrm{cu}} \quad$ cube compressive strength of concrete (MPa)

$f_{\text {Ftu }} \quad$ residual tensile strength of SFRC at $1.5 \mathrm{~mm}$ crack width (MPa)

$f_{\mathrm{R} 3} \quad$ residual flexural strength of SFRC corresponding to a crack mouth opening displacement of $2.5 \mathrm{~mm}(\mathrm{MPa})$

$H \quad$ section height $(\mathrm{mm})$

$L_{\mathrm{f}} \quad$ length of steel fibres $(\mathrm{mm})$

$M_{\text {ACT }} \quad$ observed moment

$M_{\text {cr }} \quad$ moment at first crack $(\mathrm{kNm})$

$M_{\mathrm{EL}} \quad$ elastic moment

$M_{\mathrm{n}} \quad$ negative moment at interior support $(\mathrm{kNm})$

$M_{\text {po1 }} \quad$ positive moment at mid-span $1(\mathrm{kNm})$

$M_{\mathrm{po} 2} \quad$ positive moment at mid-span $2(\mathrm{kNm})$

$P$

$T$

$V_{\mathrm{f}}$

$w_{\mathrm{u} 2}$ $\eta_{1}$

$\eta_{2}$

$\psi$

\section{Introduction}

In continuous flexural members, the ductility of sections at continuous supports allows the redistribution of moments, leading to higher load-carrying capacities (Beeby, 1997; CEBFIP, 1998; Eligehausen and Langer, 1987). The advantage of moment redistribution is evident in members reinforced with traditional steel bars, by which the amount of reinforcement at the supports could be reduced accordingly in design (Bagge et al., 2014; CEB-FIP, 1998; Eligehausen and Langer, 1987).

In recent times, steel-fibre-reinforced concrete (SFRC) flat slab systems without traditional steel bar reinforcement have gained popularity owing to the ease in construction and achievable load-carrying capacities (Destrée and Mandl, 2008; Hedebratt and Silfwerbrand, 2014; Ward, 2010). The analysis and design of continuous SFRC slab systems without traditional steel bars have been mainly carried out using the yield line theory assuming an elastic-perfectly plastic moment-curvature $(M-\phi)$ relation of SFRC sections, in accordance with the recommendation given by international standards (ACI 544.6R (ACI, 2015); SCA, 1997). This assumption is reasonably accurate in the prediction of the peak load-carrying capacity of continuous slab panels (ACI 544.6R (ACI, 2015); Destrée and Mandl, 2008; Hedebratt and Silfwerbrand, 2014). However, the assumption is applicable only for the $M-\phi$ relation plotted up to curvatures 40 to 60 times that at the first crack (ACI 544.6R (ACI, 2015); Soranakom and Mobasher, 2007). Recent studies which have established the $M-\phi$ relation of SFRC up to curvatures equal to 175 times that at the first crack indicate that 
the full moment-curvature relation is far from rigid-plastic (Venkateshwaran and Tan, 2018). In fact, it has been noted that the moment drops to nearly $40 \%$ of its peak value at very large curvatures (Venkateshwaran and Tan, 2018). Therefore, the general assumption is inadequate in representing the $M-\phi$ relation of SFRC sections; hence, the redistribution of moments that occurs in continuous slabs at the yield lines at various stages of loading.

Previous studies on moment redistribution have been extensively carried out in reinforced concrete (RC), fibre-reinforced polymer (FRP) and prestressed concrete continuous slabs (Aiello et al., 2007; Casadei et al., 2003; Cohn and Lounis, 1991; Lou et al., 2015; Oehlers et al., 2004; Rebentrost et al., 1999; Santos et al., 2013; Tajaddini et al., 2016). Limited studies on moment redistribution in SFRC slabs have been carried out (Abas et al., 2013). Abas et al. (2013) conducted tests on six two-span continuous SFRC slabs fabricated using deep trapezoidal steel sheeting (W-deck) to represent a composite bridge deck with a trapezoidal section. The purpose of the steel sheeting was to resist the tensile forces due to positive moment at the mid-span sections. At the interior support section, steel mesh reinforcement was provided at the top of the slab in three out of the six SFRC slabs. In all the slabs, the moment at the interior support dropped after first cracking, whereas those at the mid-span sections increased due to moment redistribution. However, the presence of steel mesh reinforcement in three slabs ensured that the drop in load was gradual compared to the slabs with only steel fibres. The trend in moment redistribution in these slabs was similar to RC slabs. Nevertheless, no literature is available for SFRC slabs devoid of traditional reinforcement.

In this study, the moment redistribution in continuous oneway SFRC slab panels was investigated by conducting tests on seven two-span concrete slabs reinforced with varying fibre dosages and fibre end configurations. An analytical approach using the complete $M-\phi$ relation of SFRC proposed by Venkateshwaran and Tan (2018) is presented to determine the moment redistribution at different stages of loading. Load-deflection curves of the test slabs are also presented and compared with the predicted results.

\section{Moment redistribution in SFRC flexural members}

\subsection{Theoretical considerations}

In SFRC slabs and beams without traditional reinforcement, test results show that the ultimate failure generally occurs by the formation and propagation of primary flexural cracks at the critical sections (Michels et al., 2012; Venkateshwaran and Tan, 2018). It has also been noted that any loading after the occurrence of first cracking at the critical sections leads to rigid-body rotation of the portions of the slab or beam about those cracked sections, which behave as hinges (Ahmadii et al.,
2012; Michels et al., 2012; Venkateshwaran and Tan, 2018). In a simply supported beam, only one crack forms and propagates near the mid-span (Venkateshwaran and Tan, 2018). In continuous SFRC slabs and beams, dominant primary cracks at multiple sections carrying the largest negative and positive moments can be expected. The moment capacities at these hinges can be established from the $M-\phi$ relation of SFRC for a given stage of loading. In this section, the phenomenon of moment redistribution in SFRC members without traditional reinforcement is first examined using the $M-\phi$ relation of SFRC by considering different loading stages in a one-way slab fixed at both its ends.

\subsection{Moment-curvature relation of SFRC without traditional reinforcement}

Figure 1 shows the constitutive stress-strain relation for SFRC in compression and tension extending up to large strains (Model Code (Fib, 2010); Venkateshwaran and Tan, 2018). In the figure, $f_{\mathrm{c}}^{\prime}$ is the cylinder compressive strength of concrete (MPa) and $f_{\text {ct }}$ is the tensile strength of SFRC (taken as equal to $0 \cdot 3\left(f_{\mathrm{c}}^{\prime}\right)^{2 / 3}$, according to the Model Code (Fib, 2010)) $(\mathrm{MPa})$. It is observed that the fibre content does not have a significant influence on the compressive strength of SFRC (Thomas and Ramaswamy, 2007)

In Figure 1, $f_{\mathrm{Ftu}}$ is the residual tensile strengths of SFRC at $1.5 \mathrm{~mm}$ crack widths given by the Model Code (Fib, 2010); Venkateshwaran and Tan, 2018)

$$
\text { 1. } f_{\mathrm{Ftu} 1}=\frac{f_{\mathrm{R} 3}}{3}
$$

in which $f_{\mathrm{R} 3}$ denotes the residual flexural strengths of SFRC corresponding to a crack mouth opening displacement (CMOD) of $2.5 \mathrm{~mm}$, measured by conducting three-point bend tests on notched prisms in accordance with EN 14651 (CEN, 2007).

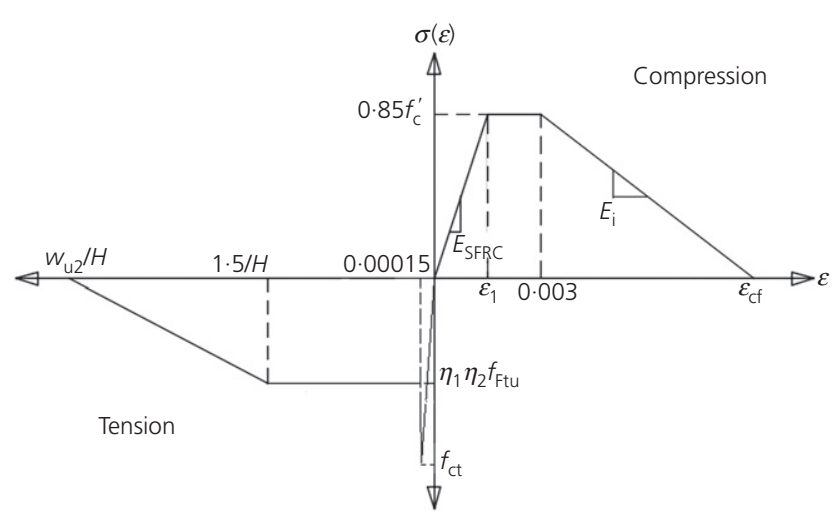

Figure 1. Constitutive stress-strain relations for SFRC in compression and tension 
Also, in Figure 1, $H$ is the section height $(\mathrm{mm}), \eta_{1}$ is a reduction factor accounting for the fibre orientation correction in flexural members with depths different from the notched prisms (Michels et al., 2012; Venkateshwaran and Tan, 2018); $\eta_{2}$ is a reduction factor accounting for the influence of the notch on pre-defining the crack path in prisms (Amin et al., 2015; Htut, 2010; Venkateshwaran and Tan, 2018); RI is the reinforcing index $\left(=V_{\mathrm{f}} L_{\mathrm{f}} / D_{\mathrm{f}}\right) ; V_{\mathrm{f}}, L_{\mathrm{f}}$ and $D_{\mathrm{f}}$ denote the volume fraction, length $(\mathrm{mm})$ and diameter $(\mathrm{mm})$ of the steel fibres, respectively; $w_{\mathrm{u} 2}$ is the crack width at which the residual tensile stress of SFRC becomes zero (see Figure 1) $\left(=\left(5-0 \cdot 2875 V_{\mathrm{f}}\right) /\left(1-0 \cdot 1845 V_{\mathrm{f}}\right) \quad(\mathrm{mm})\right) \quad($ Venkateshwaran and Tan, 2018); $E_{\mathrm{SFRC}}$ is the modulus of elasticity of SFRC $\left(=4 \cdot 58\left(f_{\text {cu }}\right)^{0 \cdot 5}+0 \cdot 42\left(f_{\text {cu }}\right)^{0.5} \mathrm{RI}+0 \cdot 39 \mathrm{RI} \quad(\mathrm{GPa})\right) \quad($ Thomas and Ramaswamy, 2007); $f_{\text {cu }}$ is the cube compressive strength of concrete $(\mathrm{MPa})$; and $E_{\mathrm{i}}$ is the slope of the descending portion of the compressive stress-strain relation $(=1930$ $\left.\mathrm{RI}^{-0 \cdot 7406}(\mathrm{GPa})\right)$ (Nataraja et al., 1999).

According to the Model Code (Fib, 2010), the crack width $w_{\mathrm{t}}$ in SFRC members is due to the strain spread over a length equal to the height of the crack. For SFRC flexural members without traditional reinforcement, this length is assumed to be approximately equal to the section depth (Model Code (Fib, 2010)). Subsequently, the tensile strain in SFRC can be defined as the corresponding crack width divided by the section depth (Model Code (Fib, 2010)), as shown in Figure 1.

In this study, $f_{\mathrm{R} 3}$ was determined based on the empirical equations developed by Venkateshwaran et al. (2018) and given as follows

$$
\text { 2. } f_{\mathrm{R}, 3}=\psi\left[0 \cdot 300\left(f_{\mathrm{c}}^{\prime}\right)^{0.5}+7 \cdot 629(\mathrm{RI})+0.373 N^{2}\right]
$$

where $\psi$ is a factor accounting for the size effect of fibres $\left(=\left(1+L_{\mathrm{f}} / 100\right)^{0.5}\right)$ and $N$ is the number of end-hooks in the steel fibres. From Equations 1 and 2, it is noted that the residual tensile strength of SFRC is significantly influenced by the fibre content. An enhancement of 120 to $160 \%$ in the residual tensile strength is observed with an increase in the fibre content from $0 \cdot 25$ to $1 \cdot 5 \%$ (Venkateshwaran and Tan, 2018).

As externally vibrated prisms used in EN 14651 (CEN, 2007) produced a higher tensile strength of about $15 \%$ (Shaaban and Gesund, 1993), the residual tensile strengths of SFRC in this study are further multiplied by a factor of 0.85 to account for the disturbance in fibre orientation due to internal vibration of the slab specimens.

Figure 2 shows the crack width, strain and stress distributions across a SFRC section in bending with a crack width, $w_{\mathrm{t}}$, at the extreme tensile fibre. The corresponding moment and curvature are $M_{\mathrm{wt}}$ and $\phi_{\mathrm{wt}}$, respectively. Using the constitutive relations in Figure 1 and considering strain compatibility, the bending moment can be established as

3. $M_{\mathrm{wt}}=C z=T z$

where $C$ is the area of the compressive stress block; $T$ is the area of the tensile stress block; and $z$ is the distance between the centroids of the compressive and tensile stress blocks.

A typical piece-wise linear moment-curvature $(M-\phi)$ relation for an SFRC section without traditional reinforcement is shown in Figure 3. There are six milestone points. Point $\mathrm{A}$ corresponds to first cracking, while points $\mathrm{B}, \mathrm{C}, \mathrm{D}, \mathrm{E}$ and $\mathrm{F}$ correspond to extreme tensile crack widths, $w_{\mathrm{t}}$, of $0.25 \mathrm{~mm}, 0.5 \mathrm{~mm}, 1.5 \mathrm{~mm}$, $5 \mathrm{~mm}$ and $w_{\mathrm{u} 2} \mathrm{~mm}$, respectively. The peak moment occurs at a $w_{\mathrm{t}}$ value of $1.5 \mathrm{~mm}$, after which, there is a significant drop in the moment up to an extreme tensile crack width of $w_{\mathrm{u} 2} \mathrm{~mm}$. The $M-\phi$ relation shown in Figure 3 has previously been

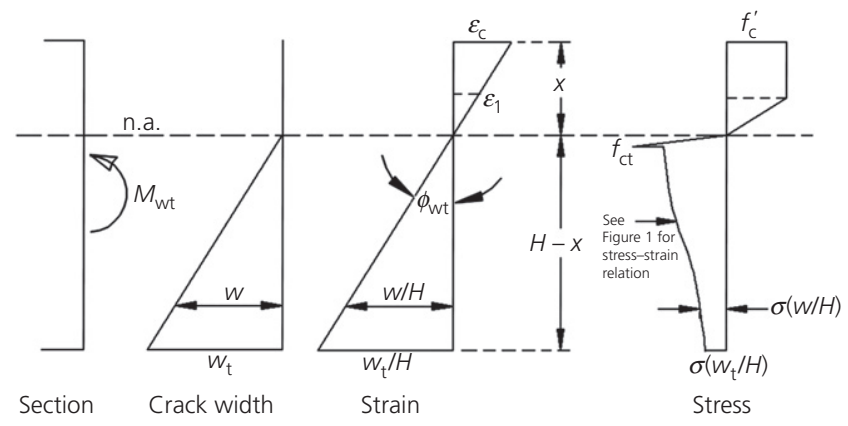

Figure 2. Crack width, strain and stress distributions across a section corresponding to an extreme tensile crack width, $w_{\mathrm{t}}$

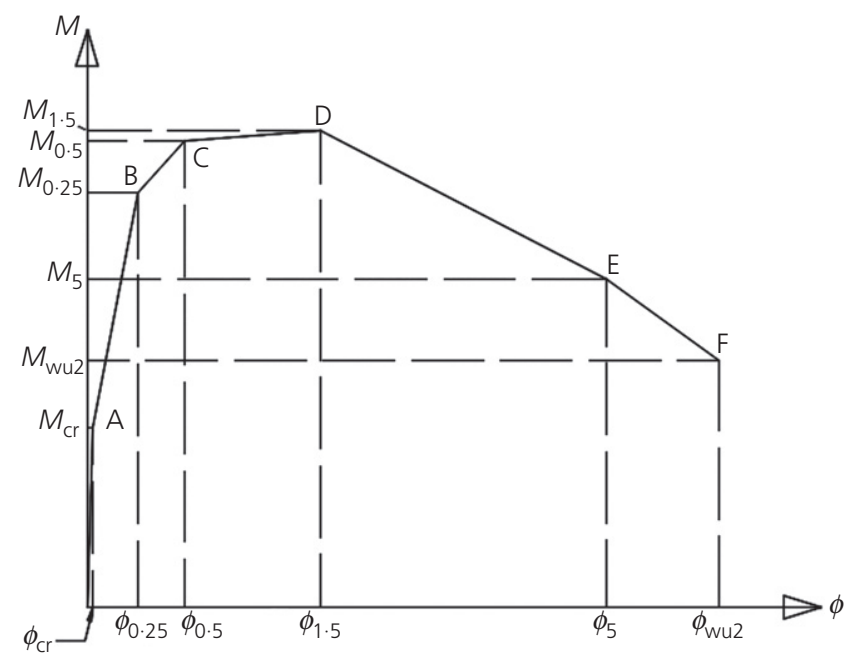

Figure 3. Moment-curvature relation for an SFRC section without traditional reinforcement 
validated using results from 24 four-point bending tests on SFRC beams (Venkateshwaran and Tan, 2018).

For the compressive strength of concrete and the range of fibre contents considered in this study, the first crack strength of SFRC, $f_{\mathrm{ct}}$, is always higher than the residual tensile strength, $f_{\mathrm{Ftu}}$, as shown in Figure 1. Although $f_{\mathrm{Ftu}}$ is lower than $f_{\mathrm{ct}}$, the moment capacity of SFRC at ultimate limit state is much higher than that at the first crack. This is owing to the large lever arm developed by the tensile stress block at the ultimate limit state compared to first crack (see Figure 2), leading to the robustness of the continuous member. Bending tests conducted on SFRC beams show that there is no sudden reduction of moment due to the reduction of stress at first crack (Susetyo, 2009; Venkateshwaran and Tan, 2018). However, there is a change in the linear elastic behaviour of SFRC after the first crack, as shown in Figure 3.

\subsection{Moment redistribution in a one-way slab fixed at its ends}

To illustrate the phenomenon of moment redistribution, consider a one-way slab fixed at both ends and subject to uniformly distributed loading, as shown in Figure 4(a). The elastic bending moment diagram for such a loading case is shown in Figure 4(b). The loading on the slab can be classified

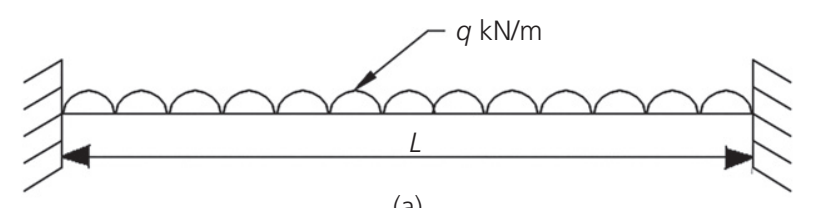

(a)

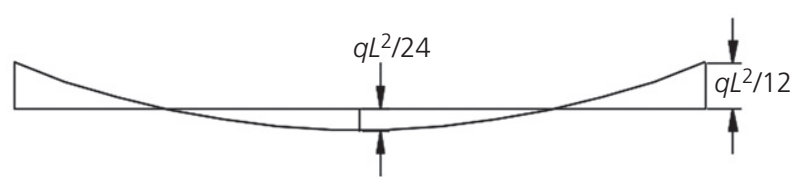

(b)

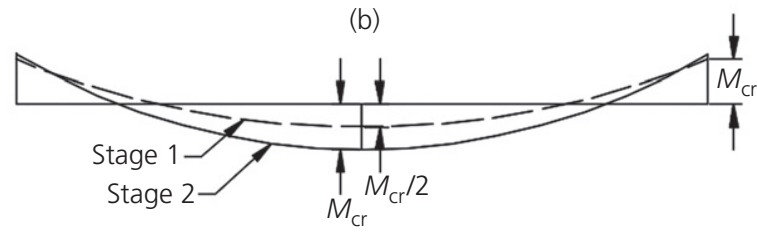

(c)

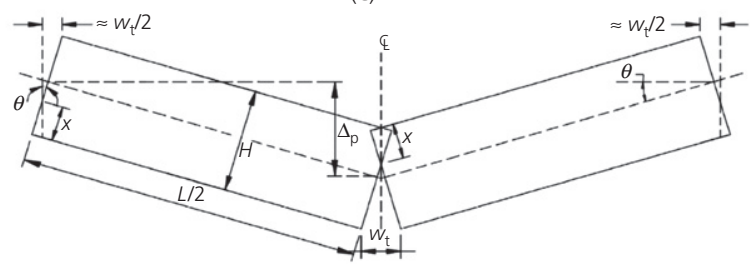

(d)

Figure 4. Elastic and plastic deformations of a one-way slab fixed at both ends: (a) one-way slab fixed at its ends; (b) elastic bending moment diagram; (c) bending moment diagrams at loading stages 1 and 2 ; (d) rigid body rotation of two halves into six stages (denoted by numbers 1 to 6 ) following the $M-\phi$ relation (denoted by milestone points A to F) in Figure 3.

The bending moment diagrams for the first two loading stages are shown in Figure 4(c). At stage 1, the concrete at the supports experiences first cracking. The moments at the supports are equal to $M_{\mathrm{cr}}$ while the span of the slab remains elastic, with the mid-span moment being $M_{\mathrm{cr}} / 2$.

At stage 2, a crack is formed at the mid-span section as well. The support moment increases by $\delta_{\mathrm{M}}$ due to the additional rotation that occurs at this section from stage 1 to stage 2 . It can be established that $\delta_{\mathrm{M}}$ is very small, thereby leading to the moments at the support regions still being approximately equal to $M_{\mathrm{cr}}$.

When the slab is further loaded, existing cracks would propagate, without formation of new cracks owing to the lesser energy requirement in the former (Ahmadii et al., 2012; Michels et al., 2012; Venkateshwaran and Tan, 2018). Subsequently, the cracks at the support and mid-span sections are expected to propagate further, leading to rigid body rotation of the slab portions between the cracks, as shown in Figure 4(d). The cracks at the mid-span and support sections behave as plastic hinges, with the entire energy being absorbed by rotation at the plastic hinges. Thus, the bending moment diagrams in Figures 4(b) and 4(c) are no longer valid.

Owing to the ductile crack-bridging action of steel fibres, it is expected that the slab sections at the mid-span and the support regions continue to hold substantial moments even after formation of plastic hinges. Figures $5(\mathrm{a})$ and $5(\mathrm{~b})$ show the moments in the mid-span and support regions, respectively, during different stages of loading after formation of the three plastic hinges in stage 2 .

Stages 3 to 6 represent the phases at which the extreme tensile crack widths at the mid-span section, $w_{\mathrm{t}}$, are $0.25 \mathrm{~mm}$, $0.5 \mathrm{~mm}, 1.5 \mathrm{~mm}$ and $w_{\mathrm{u} 2} \mathrm{~mm}$, respectively. By geometry of deformation, the extreme tensile crack widths and curvatures at the mid-span section at the corresponding stages of loading are approximately twice those at the support sections. The moments at the mid-spans and support corresponding to these extreme tensile crack widths can be obtained from Figure 5. The deflection of the slab at these stages can be established from geometrical relations (Ahmadii et al., 2012; Michels et al., 2012; Venkateshwaran and Tan, 2018).

It can be deduced that the maximum load-carrying capacity of the slab occurs at stage 5 , wherein the mid-span and support sections attain the maximum moment capacities. Figures 6(a) and 6(b) show the deviation of moments from their elastic values at the mid-span and support sections, respectively, at different stages of loading, for the one-way slab under consideration. It is seen that the moments are redistributed 


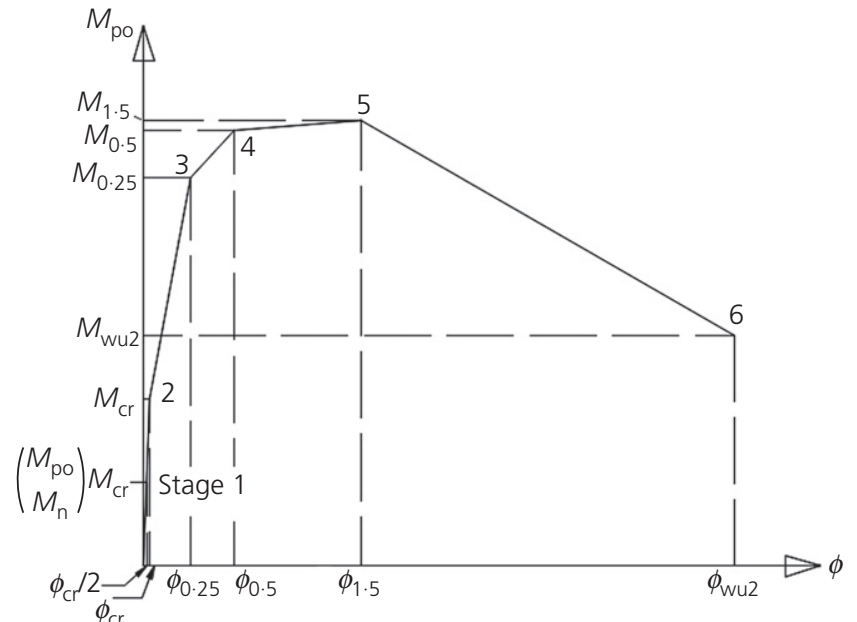

(a)

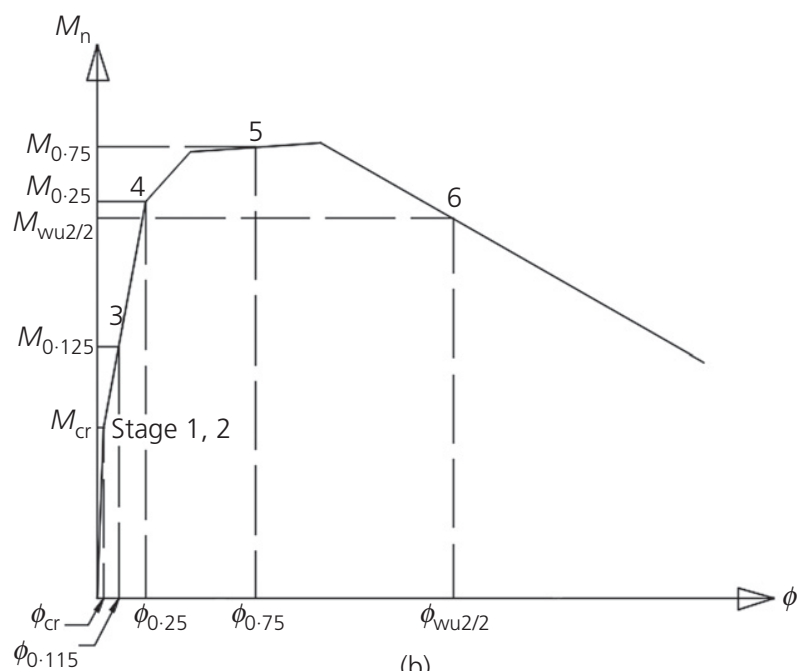

(b)

Figure 5. Moments and curvatures at (a) mid-span and (b) support section at different stages of loading

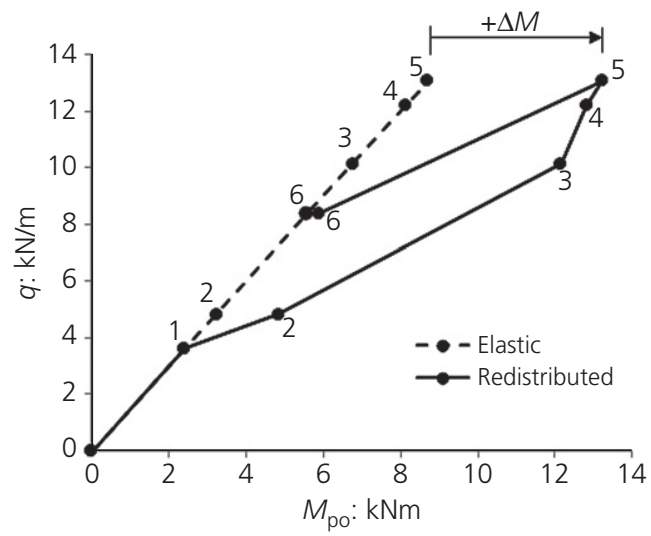

(a) from the support sections to the mid-span section. At stage 6, which signifies the final failure, there is a reduction in the degree of redistribution due to a drop in the moment at larger curvatures.

To verify the phenomenon of moment redistribution in SFRC slabs without traditional reinforcement, as presented above, an experimental programme on seven two-span, one-way continuous slabs was carried out.

\section{Experimental programme}

Table 1 shows the details of the seven two-span continuous one-way SFRC slab specimens tested in this study. Each slab had a cross-section measuring $600 \mathrm{~mm}$ wide and $120 \mathrm{~mm}$ thick. The spans were each equal to $1050 \mathrm{~mm}$. All slabs were cast with hooked-end fibres that were $60 \mathrm{~mm}$ long and $0.9 \mathrm{~mm}$ dia. The concrete mixture proportion consisted of $758 \mathrm{~kg} / \mathrm{m}^{3}$ of coarse aggregate, $871 \mathrm{~kg} / \mathrm{m}^{3}$ of fine aggregates, $400 \mathrm{~kg} / \mathrm{m}^{3}$ of cement and $240 \mathrm{~kg} / \mathrm{m}^{3}$ of water, with the concrete class targeted at $\mathrm{C}_{35 / 45}$. The actual cylinder compressive strength of the concrete ranged from $29 \mathrm{MPa}$ to $40 \mathrm{MPa}$, as shown in Table 1 . The slabs were designated $\mathrm{S}_{x y}$, where $x$ denotes the type of fibres ( 3 for $3 \mathrm{D}, 4$ for $4 \mathrm{D}$ and 5 for $5 \mathrm{D}$ ) and $y$ denotes twice the fibre volume fraction in per cent. The fibres were named based on the number of hookends, that is, 3D fibres consisted of a single hook-end while 4D and 5D fibres had 1.5 and two hook-ends, respectively (Venkateshwaran and Tan, 2018; Venkateshwaran et al., 2018).

Figure 7(a) shows the test set-up with the SFRC slab subject to centre-point loading on each span. The load was applied using a $50 \mathrm{t}$ hydraulic jack at a deflection-controlled rate of $0.1 \mathrm{~mm} / \mathrm{min}$ up to the peak load and $0.3 \mathrm{~mm} / \mathrm{min}$ thereafter. Horizontal movement was allowed at the end supports by means of rollers, as shown in Figure 7(a). Two $30 \mathrm{t}$ load

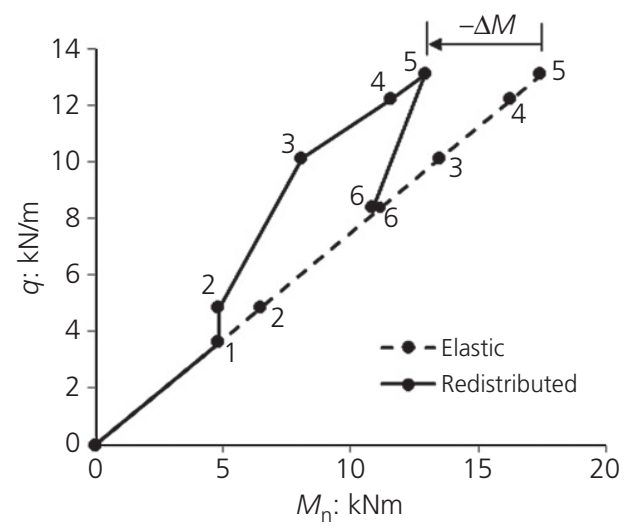

(b)

Figure 6. Expected moment redistribution at different loading stages for a one-way slab fixed at both its ends: (a) mid-span section; (b) support section 
cells were positioned below the internal support to measure the reaction. Owing to safety concerns, load cells were not placed over the roller supports. A curvature measuring device was mounted at each of the the mid-span sections of both spans and at the interior support section of the slab, with two displacement transducers positioned in the horizontal direction at the top and the bottom to measure the strains over a length

Table 1. Details of test slabs

\begin{tabular}{|c|c|c|c|c|}
\hline S no. & Label & $f_{\mathrm{c}}^{\prime}: \mathrm{MPa}$ & Fibre type & $V_{f}: \%$ \\
\hline 1 & S32 & $32 \cdot 1$ & $3 D$ & 1 \\
\hline 2 & S33 & $30 \cdot 5$ & & 1.5 \\
\hline 3 & S41 & 38.8 & $4 \mathrm{D}$ & 0.5 \\
\hline 4 & $\$ 42$ & $35 \cdot 8$ & & 1 \\
\hline 5 & 543 & $29 \cdot 6$ & & 1.5 \\
\hline 6 & S52 & 29.5 & $5 D$ & 1 \\
\hline 7 & S53 & $30 \cdot 5$ & & 1.5 \\
\hline
\end{tabular}

of $150 \mathrm{~mm}$. Linear variable displacement transducers (LVDTs) were also positioned at the two mid-span sections to measure the deflections. The tests were carried out up to a point where the load dropped substantially or until a deflection of $15 \mathrm{~mm}$, whichever occurred earlier, to capture the complete behaviour of the slab.

\section{Test results and discussion}

As the loading was designed to be symmetrical in all the seven slabs, it was theoretically expected that the mid-span deflections in both the spans would be equal throughout the loading phase. However, after formation of the first crack at the two mid-span sections, only one of them propagated further, as shown in Figure 7(b). This was due to the lesser energy required in the propagation of a single crack (i.e. the weaker one) than in simultaneous extension of both cracks (see Figure 7(b)). Consequently, no further deflection was observed at the middle of one of the spans (denoted herein as mid-span 1)

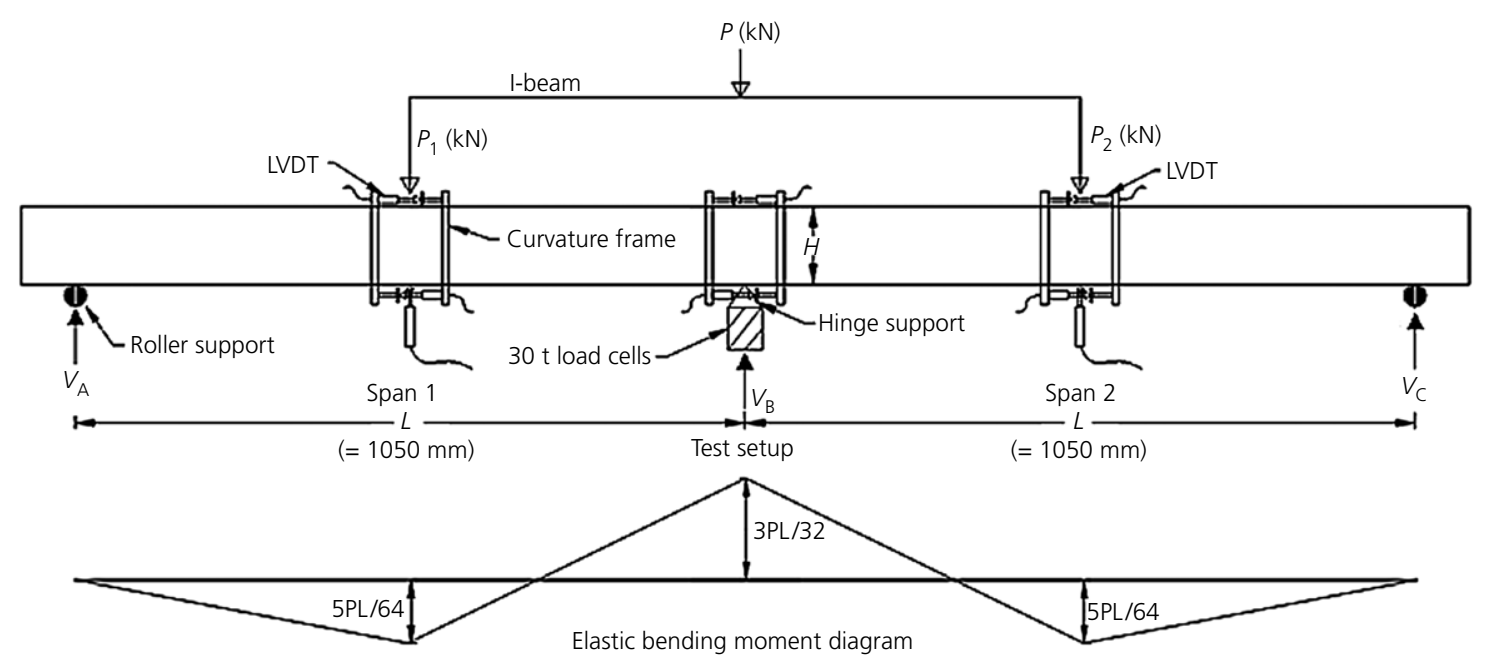

(a)

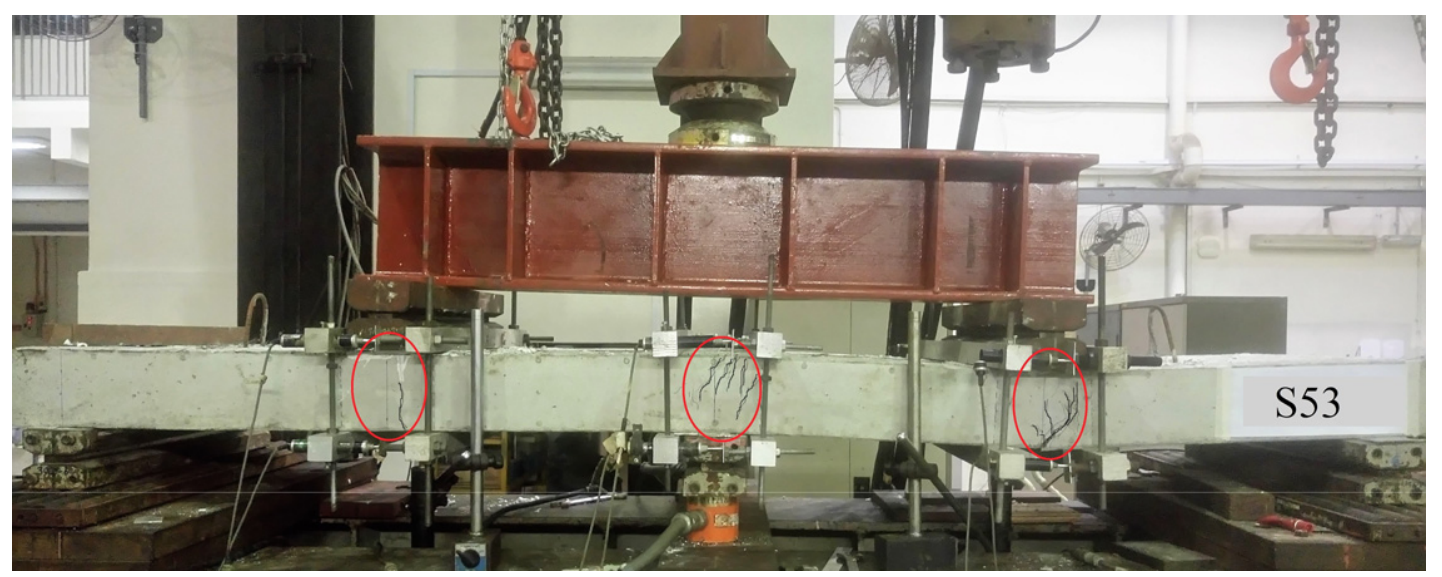

(b)

Figure 7. Test set-up of two-span continuous SFRC slab: (a) schematic diagram of test setup and elastic bending moment diagram; (b) slab after cracking 
after first cracking. Thus, after first cracking, span 1 is considered to act as a rigid body and is ignored in the analysis. The moment redistribution in span 2 alone is investigated.

The reaction $V_{\mathrm{B}}$ was measured using two $30 \mathrm{t}$ load cells. Slight deviation from elastic behaviour was recorded in the initial stages of loading owing to the low load applied. The load at first cracking was only approximately $10 \%$ of the maximum capacity of the load cells. The changes in the observed positive moments at mid-span $2, M_{\mathrm{po} 2}$, as well as the negative moment at interior support, $M_{\mathrm{n}}$, beyond the cracking moment, are plotted with respect to the applied total load, $P$, in Figures $8(\mathrm{a})-8(\mathrm{~g})$. By statics, span 2 sustains half of the total load $P$ applied by the actuator. The observed moments at various loads are compared with the elastic values typically given as $5 P L / 64$ and $3 P L / 32$ at the mid-span and the support sections, respectively, for a two-span continuous slab (see Figure 7(a)), where $L$ is the length of each span.

The behaviour of the two-span continuous RC slabs with an elastic-plastic moment-curvature relation suggests that the moment at the interior support is expected to reach its peak value first $(1,3)$. Subsequently, the moments are redistributed to the mid-span equally until all three critical sections attain their maximum values $(1,3)$. However, unlike RC slabs, the moment redistribution in SFRC slabs follows the momentcurvature relation as shown in Figure 3. After first cracking, the moments are no longer elastic and mid-span 2 attains its peak moment first, as shown in Figures $8(\mathrm{a})-8(\mathrm{~g})$. On further loading, the moments were redistributed to the interior support section until both the interior support and the midspan 2 sections attained their maximum values. Subsequently, as observed from Figures $8(\mathrm{a})-8(\mathrm{~g})$, the moments at both the mid-span 2 and the interior support drop gradually after the peak load, following the $M-\phi$ relation in Figure 3. Owing to the crack-bridging action of fibres, the slab sections were capable of sustaining moments substantially. The final deflection at stoppage of the test was approximately 5 to 6 times that at peak load.

Table 2 shows that there is only a marginal amount of moment redistribution at mid-span 2 and interior support at peak load. However, greater moment redistribution can be observed at stages other than peak load, as shown in Figures 8(a)-8(g).

At a given stage of loading, the degree of redistribution (DOR) at a critical section can be determined as follows (Lou et al., 2015)

4. $\mathrm{DOR}=\left(1-\frac{M_{\mathrm{ACT}}}{M_{\mathrm{EL}}}\right)$

where $M_{\mathrm{ACT}}$ is the observed moment and $M_{\mathrm{EL}}$ is the elastic moment.
Figures $9(\mathrm{a})-9(\mathrm{~g})$ show the degree of redistribution of moments at mid-span 2 and interior support with respect to increasing load. High degrees of redistribution were observed at the interior support and the mid-span 2 sections with increasing load. Stage 3, which indicates the state when the surface crack width at mid-span 2 is $0.25 \mathrm{~mm}$, experienced the highest the degree of redistribution in the range of $20-40 \%$. Slab S41, however, showed an anomaly in the moment redistribution trend, which could be due to a lower fibre content. The moment redistribution at the mid-span 2 and the interior support sections at peak load was generally independent of the fibre configuration.

\section{Assessment of moment redistribution in continuous slabs}

The analytical approach presented in Section 2 was used to determine the moment redistribution at various stages of loading in the continuous slabs tested in this study. The following loading stages were considered.

- Stage 1. At elastic limit - the moment at the interior support reaches $M_{\mathrm{cr}}$ while those at the mid-span sections are equal to $5 M_{\mathrm{cr}} / 6$.

- Stage 2. Cracking occurs at the mid-span sections 1 and 2.

Since the deflection at mid-span 1 is negligible, span 2 can be assumed to deflect as in Figure 5; that is, the extreme tensile crack width and the curvature at the mid-span 2 section are assumed to be twice those at the interior support section. Thus, in loading stages 3 to 6 , the moments at mid-span $2, M_{\mathrm{po} 2}$, and the interior support, $M_{\mathrm{n}}$, are respectively, given by Figures 5(a) and 5(b). In addition to the six stages explained in Section 2, stages $5 \mathrm{a}$ and $5 \mathrm{~b}$ have been added in this section between stages 5 and 6 for better illustration of moment redistribution. Stages 5, 5a and $5 \mathrm{~b}$ represent the stages wherein the moments at the mid-span 2 section correspond to extreme tensile crack widths of $1.5 \mathrm{~mm}, 3 \mathrm{~mm}$ and $5 \mathrm{~mm}$, respectively. At the same time, the moments at the interior support section at these stages correspond to crack widths equal to half that at the mid-span 2 section, that is, $0.75 \mathrm{~mm}, 1.5 \mathrm{~mm}$ and $2.5 \mathrm{~mm}$, respectively.

Applying the virtual work method to span 2 gives the loadcarrying capacity as follows

5. $\quad P=\frac{4}{L}\left(M_{\mathrm{n}}+2 M_{\mathrm{po} 2}\right)$

The predicted moments at mid-span 2 and the interior support are plotted against the total load, $P$, in Figures $8(\mathrm{a})-8(\mathrm{~g})$. Except for slab S41 and the slabs containing 5D fibres, the proposed approach predicts the redistribution of moments quite accurately. The general trend is well predicted for most slabs. The predicted degrees of redistribution at mid-span 2 and at the interior support are shown in Figures 9(a)-9(g). 
Structures and Buildings

Volume 173 Issue 3
Moment redistribution in continuous

steel-fibre-reinforced concrete slabs

Venkateshwaran and Tan
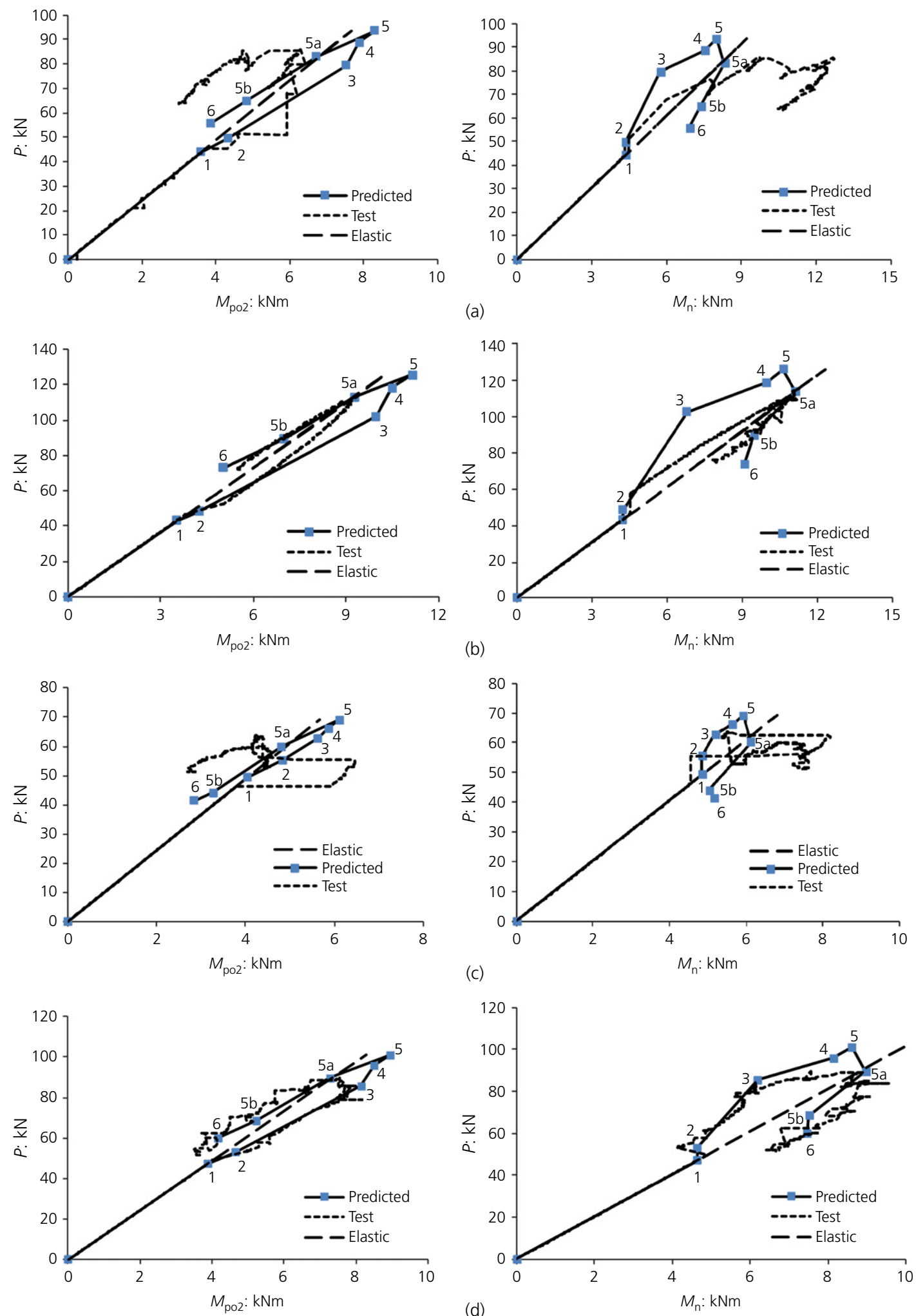

Figure 8. Load plotted against moment at mid-span and interior support sections: (a) S32; (b) S33; (c) S41; (d) S42; (e) S43; (f) S52; (g) S53 (continued on next page) 
Structures and Buildings Volume 173 Issue 3
Moment redistribution in continuous

steel-fibre-reinforced concrete slabs

Venkateshwaran and Tan
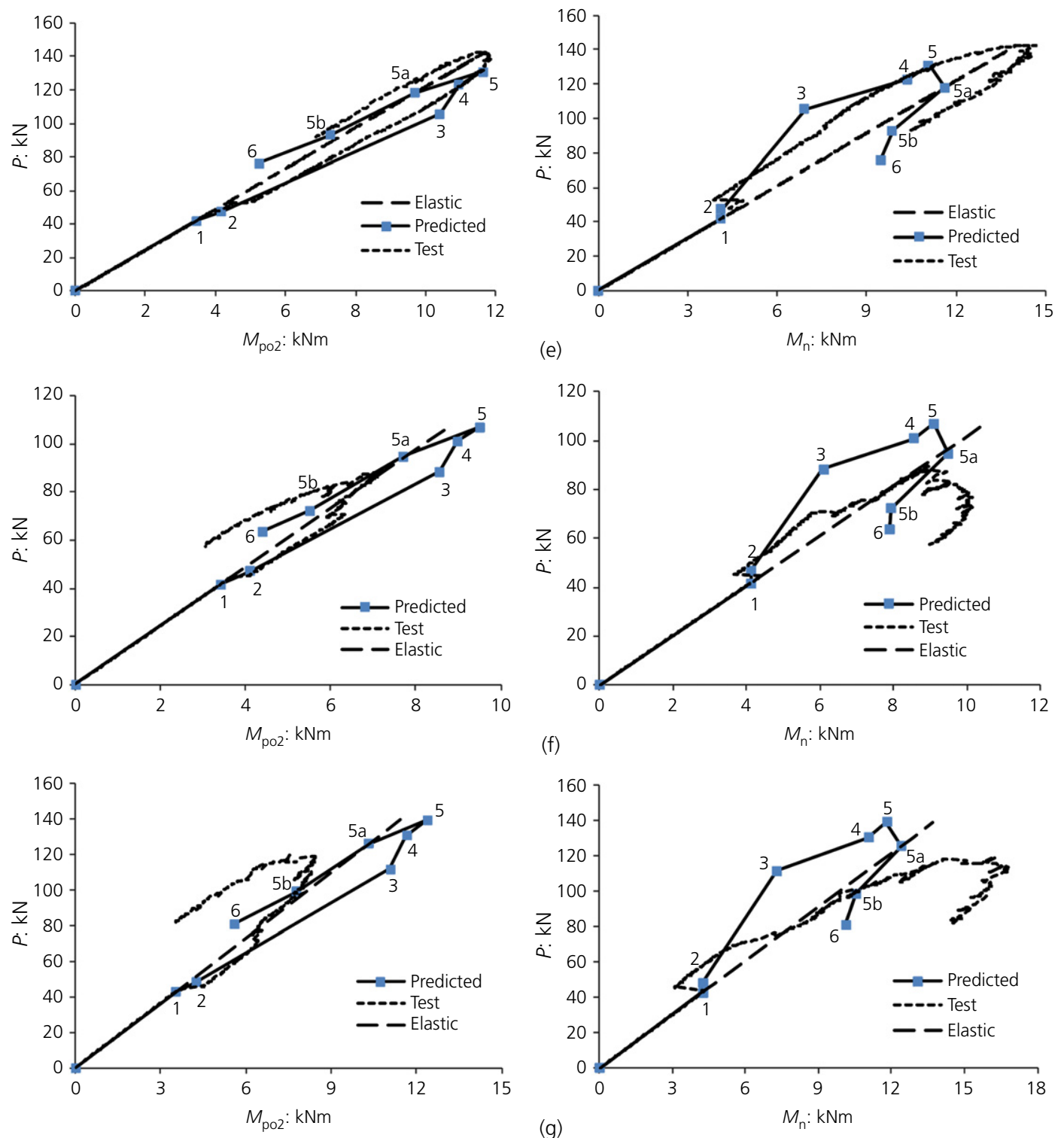

Figure 8. Continued

Table 2. Observed and elastic values of moments at peak load

\begin{tabular}{|c|c|c|c|c|c|c|c|}
\hline Slab label & Peak load, $P$ : kN & $M_{\mathrm{n}, \mathrm{TEST}}: \mathrm{kNm}$ & $M_{\mathrm{n}, \mathrm{EL}}: \mathrm{kNm}$ & $M_{\mathrm{n}, \mathrm{TEST}} / M_{\mathrm{n}, \mathrm{EL}}$ & $M_{\text {po2,TEST: }}: \mathrm{kNm}$ & $M_{\mathrm{po2}, \mathrm{EL}}: \mathrm{kNm}$ & $M_{\mathrm{po} 2, \mathrm{TEST}} / M_{\mathrm{po2}, \mathrm{EL}}$ \\
\hline M32 & $86 \cdot 0$ & $9 \cdot 73$ & 8.5 & $1 \cdot 15$ & $6 \cdot 42$ & 7.05 & 0.91 \\
\hline M33 & 114.9 & $11 \cdot 24$ & $11 \cdot 3$ & 0.99 & $9 \cdot 46$ & $9 \cdot 42$ & 1.00 \\
\hline M41 & $63 \cdot 7$ & $3 \cdot 88$ & $6 \cdot 27$ & 0.62 & $6 \cdot 43$ & $5 \cdot 23$ & 1.23 \\
\hline M42 & $72 \cdot 1$ & $7 \cdot 50$ & $8 \cdot 8$ & 0.85 & 8.00 & $7 \cdot 35$ & 1.09 \\
\hline M43 & $142 \cdot 5$ & $14 \cdot 41$ & $14 \cdot 0$ & 1.03 & $11 \cdot 50$ & $11 \cdot 69$ & 0.98 \\
\hline M52 & $89 \cdot 5$ & 8.96 & $8 \cdot 8$ & 1.02 & $7 \cdot 26$ & $7 \cdot 34$ & 0.99 \\
\hline \multirow[t]{3}{*}{ M53 } & $119 \cdot 7$ & $16 \cdot 24$ & $11 \cdot 8$ & $1 \cdot 38$ & $7 \cdot 58$ & $9 \cdot 82$ & 0.77 \\
\hline & & & Ave & 1.01 & & & $1 \cdot 00$ \\
\hline & & & Std dev. & $0 \cdot 24$ & & & $0 \cdot 14$ \\
\hline
\end{tabular}

Note: Subscripts TEST and EL indicate observed and elastic values, respectively 

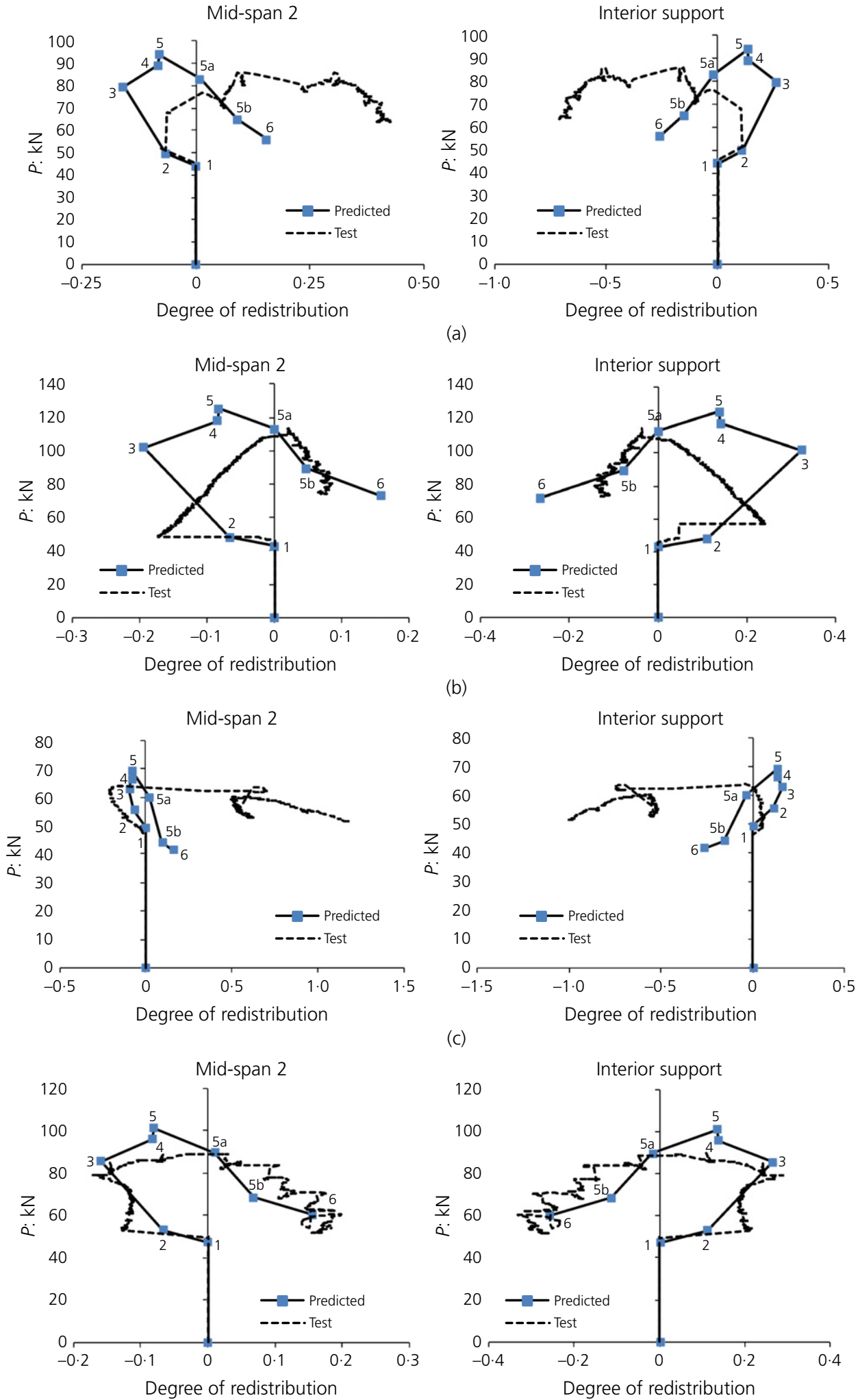

(d)

Figure 9. Degree of moment redistribution: (a) S32; (b) S33; (c) S41; (d) S42; (e) S43; (f) S52; (g) S53 (continued on next page) 

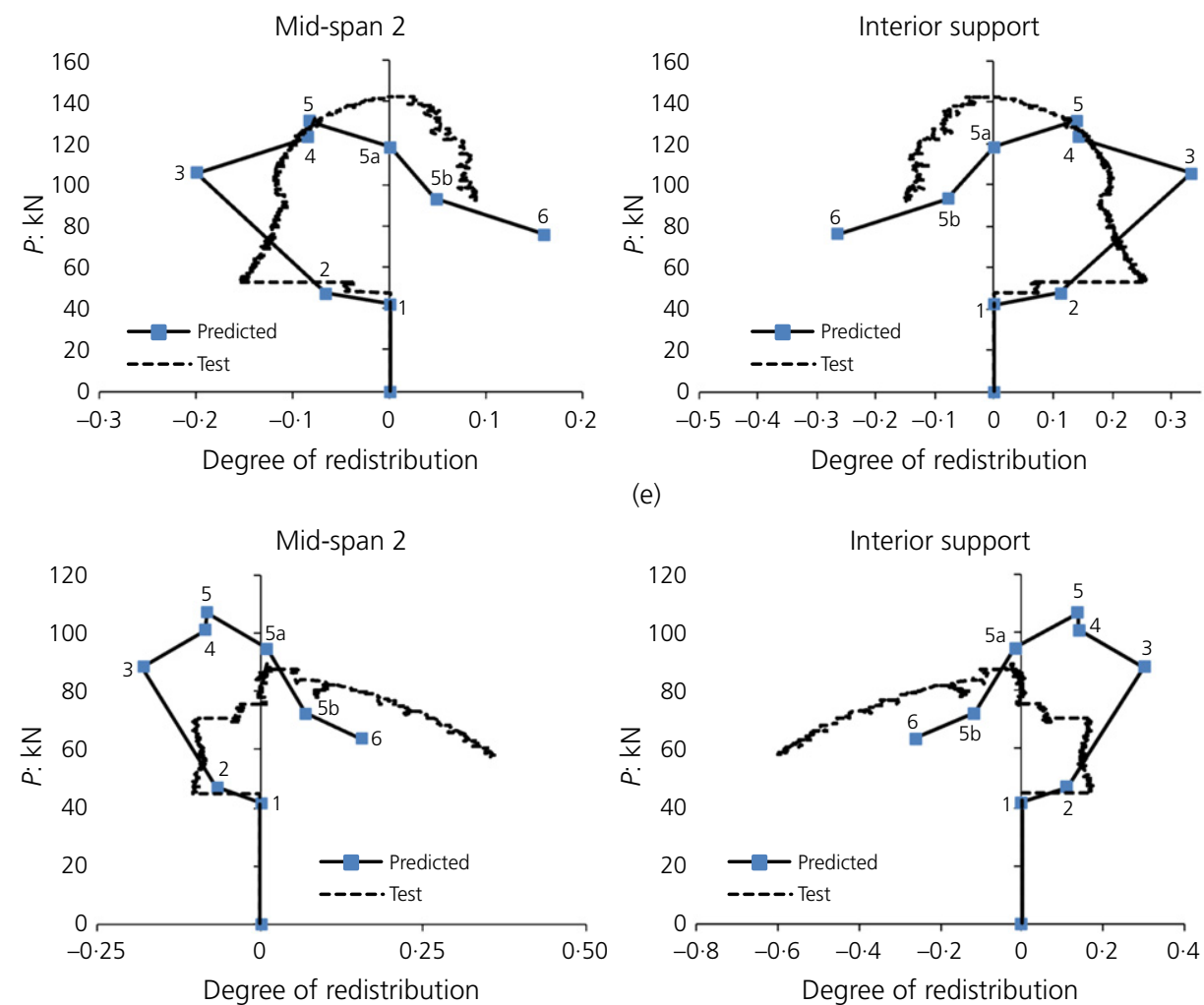

(e)
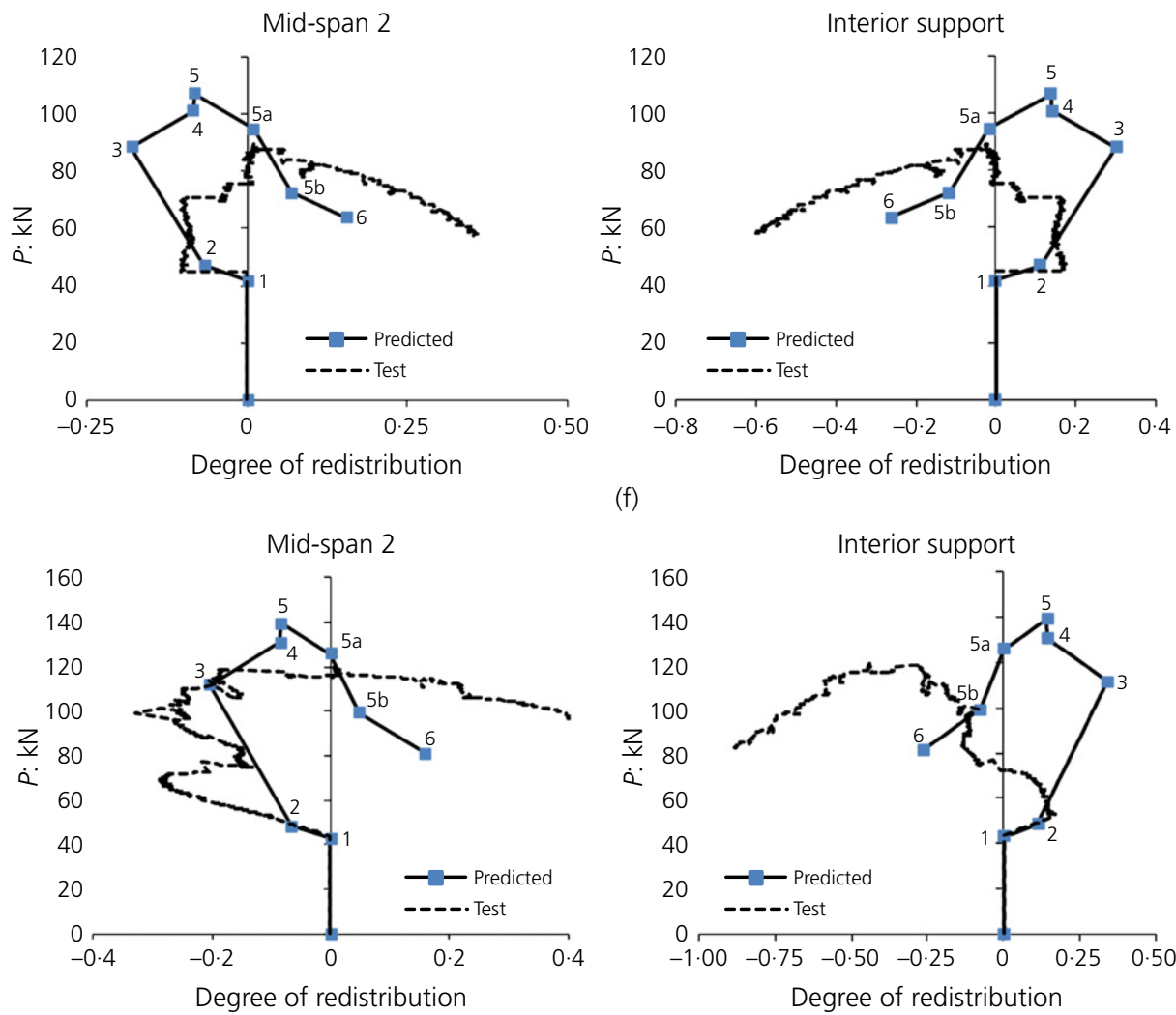

(f)

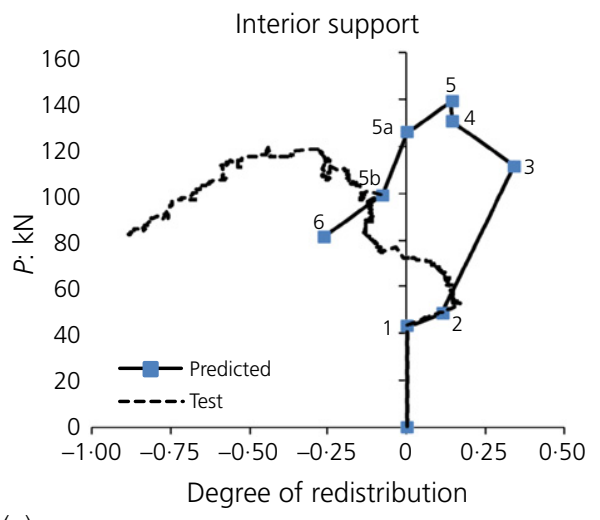

(g)

Figure 9. Continued

\section{Load-deflection relation}

The moments at the mid-spans and support sections at various loading stages are used to determine the deflections of individual spans in continuous SFRC slab systems. With the deformed shape of span 2 being similar to the rigid body rotation of the slab halves shown in Figure 4(d), the total deflection at mid-span 2 for a given extreme tensile crack width, $w_{\mathrm{t}}$, is determined as (Venkateshwaran and Tan, 2018)

6. $\Delta=\Delta_{\mathrm{cr}}+\Delta_{\mathrm{p}}=\Delta_{\mathrm{cr}}+\frac{w_{\mathrm{t}} L}{4(H-x)}$ where $\Delta_{\mathrm{cr}}$ is the elastic deflection up to first cracking (mm); $\Delta_{\mathrm{p}}$ is the plastic deformation due to rigid body rotation ( $\mathrm{mm}$ ); and $x$ is the neutral axis depth at mid-span 2 corresponding to a given loading stage ( $\mathrm{mm})$.

The observed and predicted load-deflection curves using Equations 5 and 6 are shown in Figures 10(a)-10(g). The figures also show the predicted and observed load plotted against curvature relations for the mid-span 2 and interior support sections. The analytical approach accurately predicts the load-deflection profile of most slabs. As shown in Table 3, the analytical method predicts the average peak load-carrying capacity of the slabs 

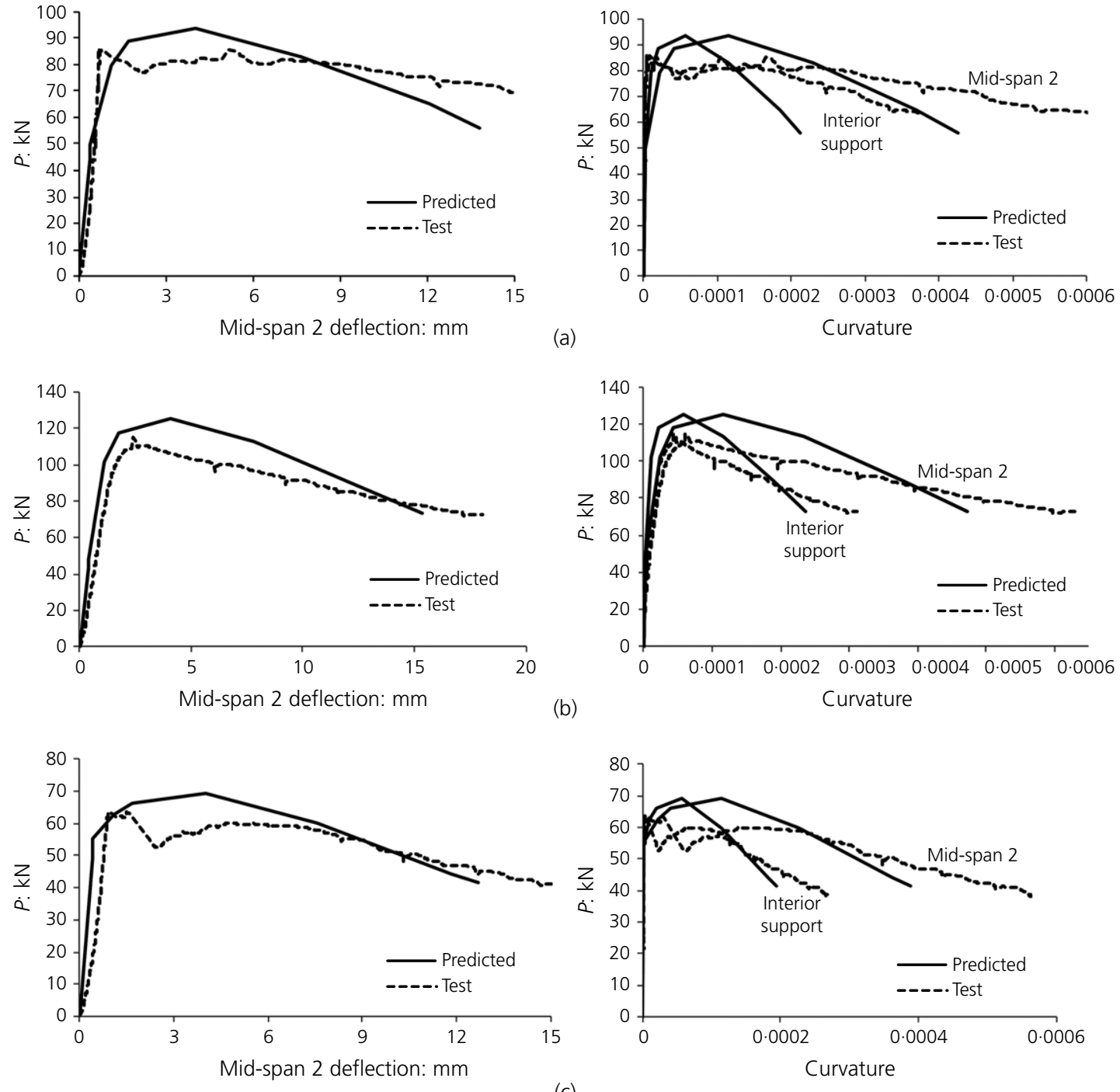

(c)
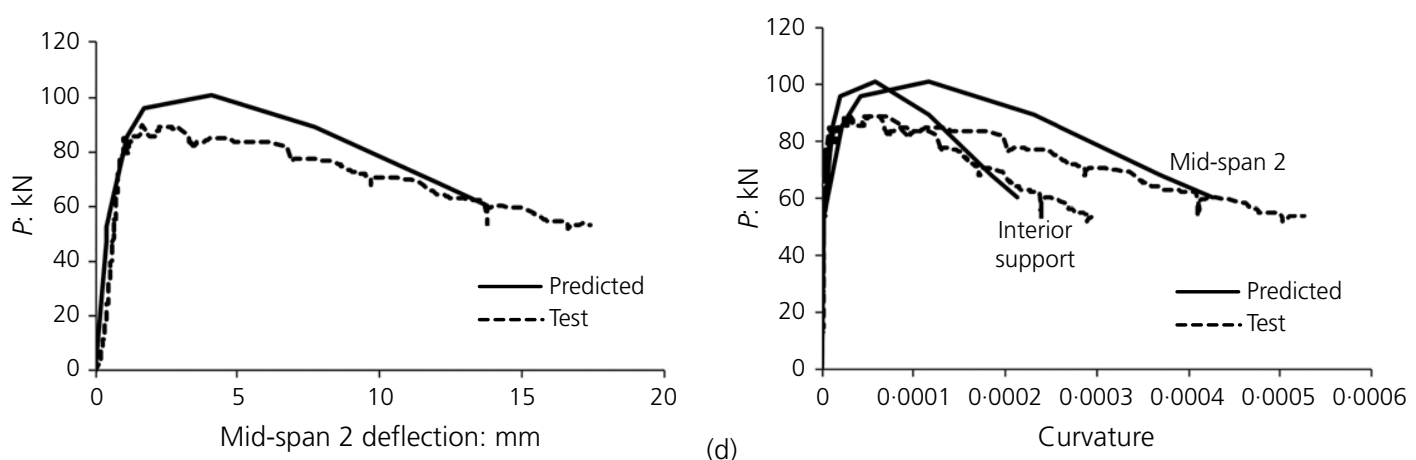

Figure 10. Deflection and curvatures: (a) S32; (b) S33; (c) S41; (d) S42; (e) S43; (f) S52; (g) S53 (continued on next page)

within $8 \%$ of the observed values with a standard deviation of $8 \%$. As expected, an increase in the load-carrying capacity of the continuous slabs is observed with an increase in fibre content. The fibre configuration did not have a significant influence on the load-carrying capacity for the given range of parameters.

\section{Conclusion}

The phenomenon of moment redistribution that occurs in continuous SFRC slabs without traditional reinforcement was investigated by conducting centre-point load tests on seven two-span, one-way slabs with varying fibre content and fibre 

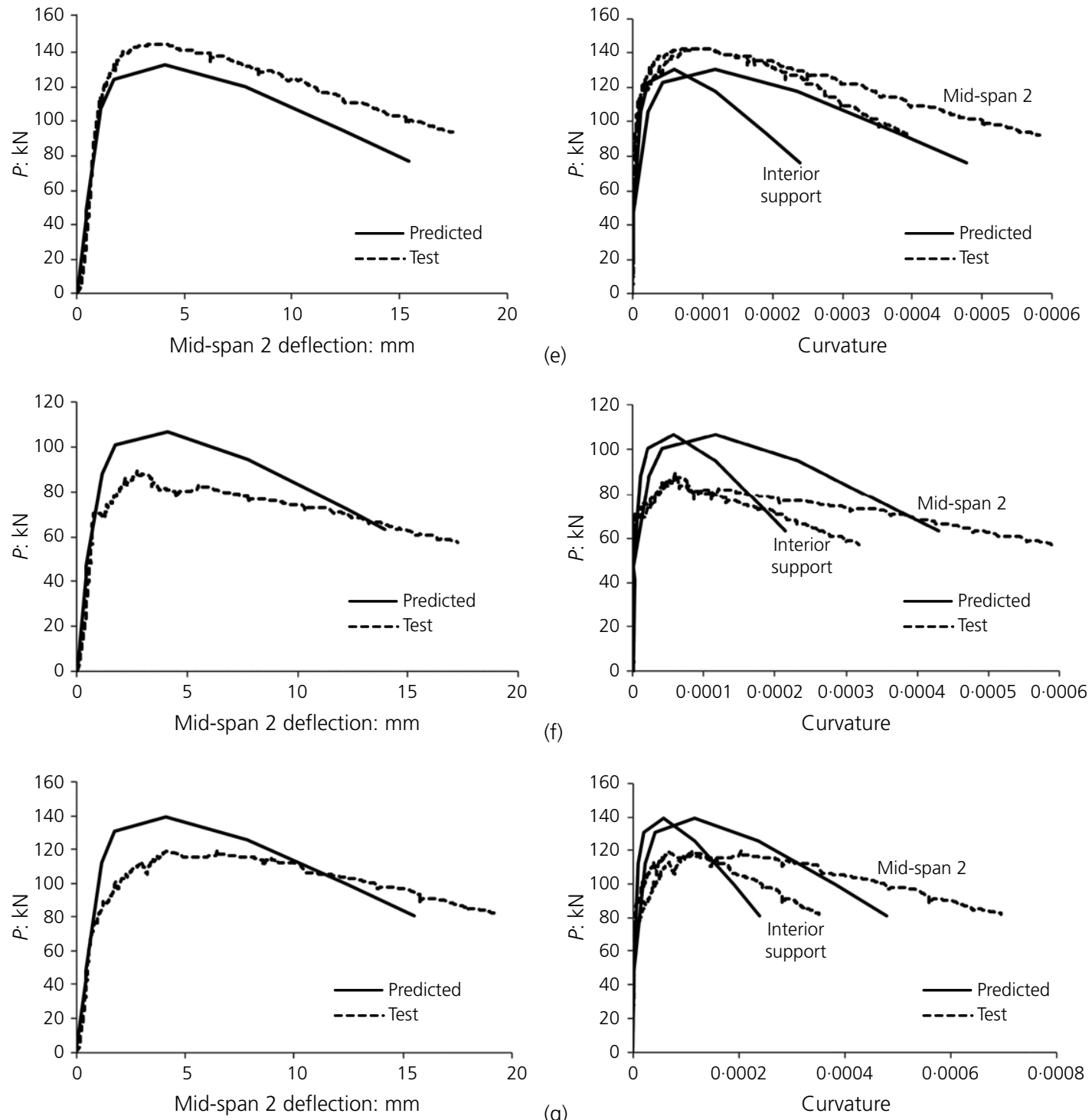

Figure 10. Continued

Table 3. Load-carrying capacity of test slabs

\begin{tabular}{|c|c|c|c|}
\hline Slab label & $P_{\mathrm{TEST}}: \mathrm{kN}$ & $P_{\text {PRED }}: \mathrm{kN}$ & $\boldsymbol{P}_{\mathrm{TEST}} / \boldsymbol{P}_{\mathrm{PRED}}$ \\
\hline S32 & $86 \cdot 0$ & $93 \cdot 7$ & 0.92 \\
\hline S33 & 114.9 & $125 \cdot 4$ & 0.92 \\
\hline S41 & $63 \cdot 7$ & $69 \cdot 1$ & 0.92 \\
\hline S42 & $89 \cdot 5$ & 101.0 & 0.89 \\
\hline S43 & 142.5 & 130.8 & 1.09 \\
\hline S52 & 89.5 & $106 \cdot 9$ & 0.84 \\
\hline \multirow[t]{3}{*}{ S53 } & 119.7 & $139 \cdot 3$ & 0.86 \\
\hline & & Ave & 0.92 \\
\hline & & Std dev. & 0.08 \\
\hline
\end{tabular}

Note: Subscripts TEST and PRED indicate observed and predicted values, respectively configuration. Considerable moment redistributions at critical sections were noted after first cracking. An analytical approach was presented which predicts the redistribution of moments well at various stages of loading for most slabs. The load-deflection behaviour was also plotted accurately for most test slabs. With test results validating the analytical approach, the moments in internal panels of a SFRC flat slab system, for example, can be predicted and expected to follow the trend shown in Figure 6.

\section{Acknowledgements}

The authors acknowledge the support of Bekaert Singapore Pte Ltd for providing the steel fibres used in the research work. The authors also thank the staff and technicians in the Structural Engineering Laboratory, National University of Singapore for their assistance in executing the test programme. 


\section{REFERENCES}

Abas FM, Gilbert RI, Foster SJ and Bradford MA (2013) Strength and seviciability of continuous composite slabs with deeep trapezoidal steel decking and steel fiber reinforced concrete. Engineeering Structures 49: 866-875.

$\mathrm{ACl}$ (American Concrete Institute) (2015) 544.6R: report on the design and construction of steel fiber-reinforced concrete elevated slabs. American Concrete Institute, Farmington Hills, MI, USA.

Ahmadii R, Ghoddousi P and Sharifi M (2012) A simple solution for prediction of steel fiber reinforcd concrete behavior under flexure. International Journal of Civil Engineering 10(4): 274-279.

Aiello MA, Valente L and Rizzo A (2007) Moment redistribution in continuous reinforced concrete beams strengthened with carbon-fiber-reinforced polymer laminates. Mechanics of Composite Materials 43(5): 453-466.

Amin A, Foster SJ and Muttoni A (2015) Derivation of the $\sigma-w$ relationship for SFRC from prism bending tests. Structural Concrete 16(1): 93-105.

Bagge N, O'Connor A, Elfgren L and Pedersen C (2014) Moment redistribution in $\mathrm{RC}$ beams - a study of the influence of longitudinal and transverse reinforcement ratios and concrete strength. Engineering Structures 80: 11-23.

Beeby AW (1997) Ductility of reinforced concrete why it is needed and how it is achived response. The Structural Engineer 75(18): 311-318.

Casadei P, Nanni A, Galati N, Ibell T and Denton S (2003) Moment redistribution in continuous CFRP strengthened concrete members: experimental results. Proceedings of International Conference Composites in Construction (CCC2003), Rende (Cosenza), Italy, pp. 307-312.

CEB-FIP (1998) Ductility of Reinforced Concrete Structures. CEB-FIP, Lausanne, Switzerland, Bulletin d'Information 242.

CEN (2007) EN 14651: test method for metallic fibred concrete measuring the flexural tensile strength (limit of proportionality (LOP), residual). CEN, Brussels, Belgium, pp. 1-17.

Cohn MZ and Lounis Z (1991) Moment redistribution in structural concrete codes. Canadian Journal of Civil Engineering 18(1): $97-108$.

Destrée X and Mandl J (2008) Steel fibre only reinforced concrete in free suspended elevated slabs: case studies, design assisted by testing route, comparison to the latest SFRC standard documents. In Tailor Made Concrete Structures (Walraven JC and Stoelhorst D (eds). CRC Press/Balkema, Leiden, The Netherlands, pp. 437-443.

Eligehausen R and Langer P (1987) Rotation Capacity of Plastic Hinges and Allowable Moment Redistribution. Comité Euro-International du Béton, Paris, France, Bulletin d'Information no. 175 .

Fib (Fédération Internationale du Béton) (2010) Fib Model Code for Concrete Structures 2010. Fib, Lausanne, Switzerland.

Hedebratt J and Silfwerbrand J (2014) Full-scale test of a pile supported steel fibre concrete slab. Materials and Structures 47(4) 647-666.

Htut TNS (2010) Fracture Processes in Steel Fibre Reinforced Concrete. PhD thesis, The University of New South Wales, Sydney, NSW, Australia.

Lou T, Lopes SMR and Lopes AV (2015) Neutral axis depth and moment redistribution in FRP and steel reinforced concrete continuous beams. Composites Part B: Engineering 70: 44-52.

Michels J, Waldmann D, Maas S and Zürbes A (2012) Steel fibers as only reinforcement for flat slab construction - experimental investigation and design. Construction and Building Materials 26(1): 145-155.

Nataraja MC, Dhang N and Gupta AP (1999) Stress-strain curves for steel-fiber reinforced concrete under compression. Cement and Concrete Composites 21(5-6): 383-390.
Oehlers DJ, Ju G, Liu IST and Seracino R (2004) Moment redistribution in continuous plated RC flexural members. Part 1: neutral axis depth approach and tests. Engineering Structures 26(14): 2197-2207.

Rebentrost M, Wong KW and Warner RF (1999) Moment redistribution and rotation capacity in prestressed concrete structures. Proceedings of the 16th Australasian Conference on the Mechanics of Structures and Materials, Sydney, Australia, pp. 97-102.

Santos P, Laranja G, Franca PM and Correia JR (2013) Ductility and moment redistribution capacity of multi-span $\mathrm{T}$-section concrete beams reinforced with GFRP bars. Construction and Building Materials 49: 949-961.

SCA (Swedish Concrete Association) (1997) Steel Fibre Concrete Recommendations for Design, Execution and Testing. Swedish Concrete Association, Stockholm, Sweden, concrete report no. 4.

Shaaban A and Gesund H (1993) Splitting tensile strength of steel fiber reinforced concrete cylinders consolidated by rodding or vibrating. ACI Materials Journal 90(4): 366-369.

Soranakom C and Mobasher B (2007) Closed-form solutions for flexural response of fiber-reinforced concrete beams. Journal of Engineering Mechanics 133(8): 933-941.

Susetyo J (2009) Fibre Reinforcement for Shrinkage Crack Control in Prestressed, Precast Segmental Bridges. PhD thesis, University of Toronto, Toronto, ON, Canada.

Tajaddini A, Ibell T and Darby A (2016) Quantifying moment redistribution in FRP-strengthened RC beams. Proceedings of the Institution of Civil Engineers - Structures and Buildings 169(11): 853-862, https://doi.org/10.1680/jstbu.15.00126.

Thomas J and Ramaswamy A (2007) Mechanical properties of steel fiber-reinforced concrete. Journal of Materials in Civil Engineering 19(5): 385-392.

Venkateshwaran A and Tan KH (2018) Load-carrying capacity of steel fibre reinforced concrete beams at large deflections. Structural Concrete 19(3): 670-683, https://doi.org/10.1002/suco.201700129.

Venkateshwaran A, Tan KH and Li Y (2018) Residual flexural strengths of steel fiber reinforced concrete with multiple hooked-end fibers. Structural Concrete 19(2): 352-365, https://doi.org/10.1002/suco. 201700030.

Ward P (2010) SFRC suspended slabs in flexure. Structural Engineer 88(1): 16-19.

\section{How can you contribute?}

To discuss this paper, please email up to 500 words to the editor at journals@ice.org.uk. Your contribution will be forwarded to the author(s) for a reply and, if considered appropriate by the editorial board, it will be published as discussion in a future issue of the journal.

Proceedings journals rely entirely on contributions from the civil engineering profession (and allied disciplines). Information about how to submit your paper online is available at www.icevirtuallibrary.com/page/authors, where you will also find detailed author guidelines. 